\title{
El islam del Raval: sus oratorios y organizaciones
}

\author{
Guillermo Martín-Sáiz \\ Washington University in St. Louis \\ guillermo@wustl.edu
}

Resumen: Dada la larga y controvertida relación entre España y Marruecos, la investigación sobre islam en España ha abordado de manera abundante y notable la presencia de mezquitas controladas por marroquies en todo el país. Por consiguiente, espacios similares controlados por paquistanies y bangladeshies, dos comunidades que en las últimas décadas han crecido rápidamente en varios puntos del país, han quedado poco explorados. Con ello, el modo en que esos espacios sirven a organizaciones islámicas de origen paquistani y bangladeshi para hacer proselitismo (dawab) entre musulmanes de esos orígenes ha quedado por explorar también. Partiendo de Cataluña y, concretamente, de Barcelona y el barrio de El Raval, donde en los últimos años dichos espacios, organizaciones y comunidades han proliferado más y de forma más rápida, este artículo quiere contribuir a ese (relativamente) nuevo terreno de investigación. Por supuesto, en países como el Reino Unido, donde, por motivos históricos $y$ políticos obvios, dichos espacios, organizaciones y comunidades tienen un largo recorrido, muchos han desarrollado dicho terreno de investigación. No obstante, el hecho de que en España, Cataluña, Barcelona y El Raval tal recorrido se halle todavía en sus primeros pasos nos permite observar y analizar de manera privilegiada, precisamente, el modo en que se establece el vinculo entre determinados espacios, organizaciones $y$ comunidades. Asi pues, partiendo de una etnografía en el barrio de El Raval, tratando de evitar generalizaciones para introducir matices, este artículo quiere contribuir también a comprender la naturaleza de dicho vinculo, por supuesto, sin darla por sentada.

Palabras clave: islam, musulmanes, oratorios, organizaciones, El Raval. 


\section{The Islam of the Raval: its orators and organizations}

Abstract: The long and controversial relationship between Spain and Morocco has led to a abundant research on Islam in Spain and the presence of mosques controlled by Moroccans across the country. However, similar spaces controlled by Pakistanis and Bangladeshis, two communities that have grown rapidly in several parts of the country within the past decades, have remained underexplored. For this reason, the way in which similar spaces controlled by Pakistani and Bangladeshi Islamic organizations enable them to proselytize (dawah) among Muslims with the same origins has also remained underexplored. Starting in Catalonia and, specifically, in the Raval district of Barcelona where such spaces, organizations and communities have proliferated rapidly in recent years, this article aims to contribute to this (relatively) new area of research. Of course, in countries such as the United Kingdom, where for obvious historical and political reasons, such spaces, organizations and communities have had a long presence, there has been much research into this subject. In contrast, in Spain, Catalonia, Barcelona and El Raval, such develop1ments are still relatively recent and this allows us to observe and analyze in a privileged manner the precise link between certain spaces, organizations and communities. Thus, the article draws on an ethnography of the Raval district that tries to introduce nuances and avoid generalizations and thus increase understanding of the nature of such link without taking it for granted.

Keywords: Islam, Muslims, mosques, organizations, El Raval. 


\section{Introducción}

Dada la larga y controvertida relación entre España y Marruecos, la investigación sobre islam en España ha abordado de manera abundante y notable la presencia de mezquitas controladas por marroquíes en todo el país. Por consiguiente, espacios similares controlados por paquistaníes y bangladeshíes, dos comunidades que en las últimas décadas han crecido rápidamente en varios puntos del país, han quedado poco explorados. Con ello, el modo en que esos espacios sirven a organizaciones islámicas de origen paquistaní y bangladeshí para hacer proselitismo (dawah) entre musulmanes de esos orígenes ha quedado por explorar también ${ }^{1}$. Partiendo de Cataluña y, concretamente, de Barcelona y el barrio de El Raval, donde en los últimos años dichos espacios, organizaciones y comunidades han proliferado más y de forma más rápida, este artículo quiere contribuir a ese (relativamente) nuevo terreno de investigación ${ }^{2}$. Por supuesto, en países como el Reino Unido, donde, por motivos históricos y políticos obvios, dichos espacios, organizaciones y comunidades tienen un largo recorrido, muchos han desarrollado dicho terreno de investigación. No obstante, el hecho de que, en España, Cataluña, Barcelona y El Raval tal recorrido se halle todavía en sus primeros pasos nos permite observar y analizar de manera privilegiada, precisamente, el modo en que se establece el vínculo entre determinados espacios, organizaciones y comunidades. Así pues, partiendo de una etnografía en el barrio de El Raval, tratando de evitar generalizaciones para introducir matices, este artículo quiere contribuir también a comprender la naturaleza de dicho vínculo, por supuesto, sin darla por sentada. Empecemos por el principio.

\section{Primeros pasos}

Tras la Segunda Guerra Mundial (1939-1945), las metrópolis europeas negociaron y en muchos casos disputaron violentamente la independencia de sus colonias en África y Asia. Al mismo tiempo, la reconstrucción de los países europeos, que pasó por la revitalización de sus sectores industriales y de servicios, recurrió a mano de obra migrante procedente de las antiguas colonias en África y Asia (Soysal, 1994). Tras su llegada, esa mano de obra, asentada mayoritariamente en ciudades y, concretamente, en barrios de clase trabajadora, comenzó a organizarse en centros comunitarios que, en muchos casos, incluyeron espacios para

1 Sol Tarrés Chamorro (2012) ha trabajado sobre alguna de estas organizaciones, concretamente, en mezquitas controladas por marroquíes en Andalucía.

2 Aunque Jordi Moreras (2004) ha trabajado sobre la presencia de paquistaníes en El Raval, la presencia en este barrio de organizaciones de origen tanto paquistaní como bangladeshí (o indio) prácticamente no ha sido estudiada. 
la oración comunitaria (Metcalf et alii, 1996). Con el tiempo, esos espacios se convirtieron en lugares de culto, y dada la intensidad de encuentros y desencuentros históricos con el islam, fueron los centros de culto musulmán, es decir, las mezquitas, los que atrajeron gran interés vecinal, político y mediático (Vertovec y Peach et alii, 1997). En España, la dictadura franquista (1939-1975) retrasó el establecimiento de mezquitas hasta la transición democrática, que dio pie a la ley orgánica de libertad religiosa de 1980, el reconocimiento del notorio arraigo del islam en 1989 y el acuerdo de cooperación del Estado y las comunidades musulmanas en 1992 (Planet, 1998). Dos organizaciones creadas en ese momento, la Comisión Islámica de España y a la Junta Islámica de España, adquirieron un rol privilegiado para garantizar el cumplimiento de dicho acuerdo, incluyendo el establecimiento de mezquitas y oratorios ${ }^{3}$. Proliferando por todo el país estos espacios, es decir, los oratorios despertaron especial interés vecinal, político y mediático en Cataluña (Moreras, 1999).

Casi dos décadas después, en 2009, el Parlamento autonómico de Cataluña aprobó su propia ley sobre de centros de culto, la cual, respetando el rol de la Comisión Islámica y de la Junta Islámica, trasladó a los ayuntamientos la decisión última sobre el establecimiento de esos espacios. Como veremos, ello afectó especialmente a oratorios musulmanes, que, faltos de recursos, se toparon con la dificultad de cumplir normativas municipales sobre salud pública, incluyendo insonorización y ventilación apropiadas, sobre seguridad, incluyendo salidas de incendios (Moreras, 2009). El ejemplo más patente de esa situación, que llevó a perpetuar una patente precariedad también, resultó ser Barcelona, con apenas una treintena de oratorios situados en barrios de clase trabajadora $y$, concretamente, en almacenes y bajos de edificios residenciales, normalmente alquilados (Martínez-Ariño, Griera, García-Romeral y Forteza, 2011). De este modo, una vez más, los oratorios musulmanes suscitaron gran interés y preocupación vecinal, política y mediática (Martín-Sáiz, 2014). Concretamente, fueron los oratorios de El Raval, un barrio con una larga historia obrera, pero en pleno proceso de transformación, los que suscitaron mayor controversia (Martín-Sáiz, 2015).Y de entre todos los oratorios del barrio, fue el de Tariq ibn Ziyad, el más antiguo y el más grande también, situado entre las calles Hospital y Sant Rafael, el que suscitó más controversia. Varios años después, en 2015, contacté con su consejo (majlis) y empecé a entrevistar a sus miembros para saber por qué.

\footnotetext{
3 En el islam, las mezquitas son espacios destinados a la oración que reúnen una serie de elementos arquitectónicos tanto internos como externos que las distinguen de oratorios que, estando destinados también a la oración, no reúnen esos elementos, como minaretes. Por ese motivo, este artículo recurre al término «oratorio» (y «oratorios») para referirse a espacios que, por lo pronto, no cuentan con minaretes.
} 
Según los entrevistados, marroquíes y paquistaníes, la controversia comenzó a principios de los años setenta, cuando varios de ellos reunieron el dinero suficiente, siempre a través de donaciones de particulares, para alquilar un apartamento en un edificio residencial situado en la calle Elisabets, en El Raval. Durante varios años, este apartamento reunió a marroquíes y paquistaníes para realizar las cinco oraciones diarias (salat), desde la salida hasta la caída del sol y también por la noche. No obstante, con las protestas de los vecinos, que llevaron incluso a sellar la cerradura de la puerta de entrada al apartamento o a cambiar la cerradura de la puerta de entrada al edificio, los asistentes reunieron donaciones suficientes para alquilar otro espacio. A finales de los setenta, estos asistentes alquilaron un apartamento en un edificio residencial situado en la calle Sant Antoni Abad, en el mismo barrio, más grande y con mayor capacidad para reunir a cada vez más marroquíes y paquistaníes para realizar las cinco oraciones diarias. Sin embargo, como había ocurrido anteriormente, dadas las protestas de los vecinos, que también llevaron a cambiar la cerradura de la puerta de entrada al edificio, los asistentes volvieron a reunir donaciones suficientes para alquilar otro espacio, más grande y preferiblemente más discreto. Así, a principios de los ochenta, estos asistentes alquilaron un almacén en el patio interior de una finca de edificios residenciales situados entre las calles Hospital y Sant Rafael, en el barrio también, con entrada desde uno de los edificios situados en la calle Hospital.

Tras completar las renovaciones pertinentes, que incluyeron limpiar a fondo, pintar de blanco e instalar alfombras, baños, fuentes para abluciones ( $w u d u)$, calefactores, ventiladores y estanterías para libros, varios marroquíes y paquistaníes formaron un consejo. Este consejo se encargó de elegir el nombre de Tariq ibn Ziyad para este oratorio y un imán para el mismo, un marroquí con cierta experiencia liderando las oraciones diarias. Asimismo, ese consejo se encargó de programar esas oraciones y de reunir donaciones suficientes para cubrir los gastos de mantenimiento, incluyendo por supuesto el alquiler mensual. A lo largo de los ochenta, el número de asistentes fue creciendo y ayudó al consejo a reunir más donaciones para, a principios de los noventa, alquilar los bajos del edificio residencial que daba entrada al oratorio a través de un pequeño portal en la calle Hospital. De nuevo, a lo largo de los noventa, el número de asistentes siguió creciendo y llevó al consejo a reunir todavía más donaciones. En esta ocasión, el consejo optó por comprar los espacios con los que contaba ya el oratorio, además de los bajos y un amplio altillo en un edificio residencial colindante, situado en la calle Sant Rafael. Desde esta calle se abrió una nueva y amplia entrada, dejando el pequeño portal de la calle Hospital como salida de incendios. Con capacidad ya para más de seiscientas personas y pese a las protestas de los vecinos, este 
oratorio se consolidó como el más antiguo y más grande del barrio, pero también, como ya he mencionado, el más controvertido incluso entre los asistentes. Veamos por qué.

Desde el principio, además de las oraciones diarias, el consejo del oratorio programó varias actividades. La principal fue la lectura diaria del Corán y de varios dichos y hechos del Profeta Muhammad (hadith), normalmente extraídos de colecciones clásicas, como Sahib Bukhari ("Hadith] auténticos de [Muhammad ibn] Bukhari') y Sahih Muslim ('[Hadith] auténticos de Muslim [ibn Hajjaj]'), del siglo nueve. Tras la lectura de estos textos, tanto en árabe como en urdu, el consejo programó la lectura Fazail-e Amaal ('Virtudes de los deberes') y Muntakhab Ahadith ('Selección de hadith'), dos famosos comentarios de hadith de mediados del siglo xx publicados tanto en árabe como en urdu. Estos comentarios, centrados en los hábitos ( $a d a b)$ y deberes (amaal) de los musulmanes, subrayaban cuestiones como la higiene personal, la vestimenta y la interacción con los demás. Muchos reconocieron la importancia de estas cuestiones y vincularon comentarios como Fazail-e Amaal y Muntakhab Ahadith con la Jama'at at-Tabligh ad-Dawa ('Grupos para la propagación de la fe y el proselitismo'). Fundada en la India colonial de principios del siglo xx, esta organización islámica rechazaba prácticas sospechosas de politeísmo (shirk), como cantos dedicados a Muhammad (na’at) y a santos (pir) musulmanes (qawwali) (Sikand, 2000). Con el miedo a las protestas de los vecinos en mente, esta vez por ruido, el consejo del oratorio priorizó la lectura de Fazail-e Amaal y Muntakhab Ahadith, así como la discusión sobre la higiene personal, la vestimenta y la interacción con los demás.

\section{Primeras disputas}

Con el cambio de siglo, Tariq ibn Ziyad resultó insuficiente para albergar a cada vez más asistentes, marroquíes y paquistaníes principalmente. Por consiguiente, varios de ellos reunieron donaciones suficientes para alquilar los bajos de un edificio residencial en la calle de la Paloma, en El Raval también, con capacidad para más de doscientas personas. Tras completar las renovaciones pertinentes, varios marroquíes y paquistaníes formaron un consejo que se encargó de elegir el nombre de Madani Masjid para este oratorio y un imán para el mismo, un paquistaní con cierta experiencia liderando las oraciones diarias. Como ocurriera en Tariq ibn Ziyad, ese consejo se encargó de reunir donaciones suficientes para cubrir los gastos de mantenimiento, además de programar las oraciones diarias. Como ocurriera también en Tariq ibn Ziyad, el consejo programó la lectura diaria del Corán y de varios dichos y hechos de Muhammad extraídos de Sabih Bukhari y Sabih Muslim, tanto en árabe como en urdu, así como de Fazail-e Amaal y 
Muntakhab Ahadith, en árabe y en urdu también. De nuevo, muchos de los asistentes, como siempre, marroquíes y paquistaníes principalmente, vincularon estos títulos y la discusión de la higiene personal, la vestimenta y la interacción con los demás con la Jamáat at-Tabligh. Con esta organización y sus posiciones y el miedo a las protestas de los vecinos por ruido siempre presentes, el consejo terminó rechazando cantos dedicados a Muhammad y a santos musulmanes por ser sospechosos de politeísmo.

El vínculo de Tariq ibn Ziyad y Madani Masjid con la Jamáat at-Tabligh vinculó también a estos oratorios entre sí, y con la intención de equiparar sus actividades emprendieron un debate sobre el liderazgo (imarat) de la organización en el barrio. En el momento de su fundación, esta centró este liderazgo en su primer markaz (centro) en Delhi, conocido como Nizamuddin Markaz, desde el cual se propuso controlar markaz en Asia, África y Europa, que, a su vez, debían controlar otros markaz en estas regiones. De este modo, cada uno de estos markaz secundarios debía controlar oratorios locales, las lecturas de Fazail-e Amaal y Muntakhab Ahadith y las posteriores discusiones, sirviendo estas para hacer proselitismo al extenderlas entre vecinos musulmanes (Masud, 2000). Partiendo de esta estrategia, el consejo de Tariq ibn Ziyad, recordando la antigüedad y las dimensiones de este oratorio, propuso a esta misma como markaz en el barrio. Con ello, se aspiraba a controlar Madani Masjid, fundada posteriormente y de menores dimensiones, incluyendo sus lecturas y discusiones y, por supuesto, su proselitismo entre vecinos musulmanes. Dicho de otro modo, si Tariq ibn Ziyad debía ser el markaz de la organización en el barrio, su consejo debía ostentar su liderazgo en ese contexto, siendo, pues, ese consejo, en palabras de sus miembros, partidario del imarat. No obstante, si bien es cierto que el consejo de Madani Masjid reconoció la antigüedad y las dimensiones de Tariq ibn Ziyad, sus miembros cuestionaron la capacidad del consejo de ese oratorio para ejercer cualquier tipo de liderazgo.

Para empezar, la antigüedad y las dimensiones de un oratorio no bastaban para ejercer el liderazgo. Durante más de dos décadas, el consejo de Tariq ibn Ziyad había logrado mantener abierto e incluso ampliar ese oratorio, asegurando su supervivencia con la compra del espacio. Sin embargo, esos esfuerzos habían mantenido demasiado ocupado al consejo, que habría descuidado el estudio detallado de Fazail-e Amaal y Muntakbab Abadith para liderar discusiones y hacer proselitismo. Por su parte, el consejo de Madani Masjid debería dedicar menos esfuerzos para mantener abierto ese oratorio, de menores dimensiones y visibilidad y por ello menos controvertido. Precisamente por ese motivo, el consejo de ese oratorio podría dedicar más tiempo a prepararse para liderar discusiones 
y hacer proselitismo, aspirando así a disfrutar de cierta independencia y de un liderazgo compartido. En palabras de sus miembros, el devenir de la Jamáat atTabligh sugería esa misma estrategia. Tras la desaparición de su fundador, $\mathrm{Mu}$ hammad Ilyas Kandhlawi, en los años cuarenta, de su hijo, Muhammad Yusuf Kandhlawi, en los años sesenta, y de su sucesor al frente del markaz de Delhi y de la organización, Inamul Hasan Kandhlawi, en los años noventa, todo cambió. Incluyendo al markaz de Delhi, un total de diez markaz de todo el mundo formaron una shura ('consulta', entendida como asamblea) para compartir el liderazgo de la organización, basado en decisiones compartidas (Metcalf, 2009). A nivel local, en el barrio, esa shura debería incluir como iguales a los consejos de Tariq ibn Ziyad y de Madani Masjid.

Mientras tanto, con el cambio de siglo también, la presencia mayoritaria de marroquíes y paquistaníes en Tariq ibn Ziyad y Madani Masjid, y, por lo tanto, el uso mayoritario del árabe y del urdu en esos oratorios, despertó otra iniciativa. Con el aumento de bangladeshíes en El Raval, varios de ellos reunieron donaciones suficientes para alquilar los bajos y un pequeño altillo en un edificio residencial en la calle de la Riereta, también en el barrio, con capacidad para más de doscientas personas. Tras las renovaciones pertinentes, la formación de un consejo de bangladeshíes que se encargó de elegir a otro bangladeshí como imán y Shah Jalal Jame como nombre para este oratorio, este abrió sus puertas. Como Tariq ibn Ziyad y Madani Masjid, el consejo de este oratorio también programó la lectura diaria de dichos y hechos de Muhammad extraídos de Sabib Bukbari y Sabib Muslim, priorizó Fazail-e Amaal y Muntakhab Abadith para las posteriores discusiones, en este caso en bengalí. Una vez más, los asistentes, en este oratorio, bangladeshíes principalmente, vincularon todo ello y el rechazo a todo tipo de cantos a la Jamáat at-Tabligh. Por último, pese al vínculo con esta organización, el consejo de Shah Jalal Jame reclamó también su independencia, no solo del imarat propuesto en Tariq ibn Ziyad sino también de una posible shura junto con Tariq ibn Ziyad y Madani Masjid. En su opinión, en su origen, esas dos posibilidades estaban marcadas por el sectarismo propio de musulmanes indios y paquistaníes, presente incluso entre aquellos vinculados a la misma organización.

De hecho, la formación de una shura para compartir el liderazgo de la Jamáat at-Tabligh, en los años noventa, vino marcada por las disputas entre los diez markaz de todo el mundo que la integraron. En ese escenario, Muhammad Saad Kandhlawi, biznieto del fundador, reclamó su linaje para proponerse a sí mismo como líder del principal markaz de Delhi, el llamado Nizamuddin Markaz, así como de la organización, reclamando de ese modo recuperar el modelo del imarat para la misma. En respuesta, otros, como Muhammad Abdul Wahhab, 
del markaz de Raiwind en Lahore, Paquistán, negaron la relevancia de linajes familiares y reclamaron mantener el modelo de shura. Entrado ya el nuevo siglo, la disputas entre partidarios de uno y otro modelo se extendieron por todo el mundo, llevando a muchos markaz a, manteniendo su vínculo con la Jamáat at-Tabligh a través de Fazail-e Amaal y Muntakhab Ahadith, romper relaciones. Esta ruptura implicó al markaz de Bangladesh, pero a diferencia de los markaz de India y Paquistán y de los controlados por indios y paquistaníes, propusieron la formación de una shura en markaz bangladeshíes en todo el mundo, casi como mediadores (Malik, 2017). Siguiendo estos pasos, el consejo de Shah Jalal Jame, insistiendo en su independencia con respecto al imarat propuesto en Tariq ibn Ziyad y a una posible shura junto con Tariq ibn Ziyad y Madani Masjid, propuso liderar otra shura para mediar entre estos oratorios. En última instancia, más allá de mediar, esta propuesta sumó un nuevo contendiente a las disputas entre aquellos vinculados a la organización a nivel local.

\section{Más disputas}

Desde enero de 2008, una serie de acontecimientos añadió nuevos ingredientes a esas disputas. Durante una fría noche de ese mes, un amplio dispositivo policial conocido como la «Operación Cantata» ocupó El Raval. Esa operación llevó a cabo varias detenciones en apartamentos y negocios del barrio y en Tariq ibn Ziyad. Esas detenciones llevaron a catorce ciudadanos indios y paquistaníes, muchos de ellos miembros del consejo de ese oratorio y vinculados a la Jamáat at-Tabligh, a pasar la noche en dependencias policiales. Al día siguiente, la policía liberó a tres de ellos y trasladó a Madrid a los otros once, conocidos como desde entonces como «Los once de El Raval». Una vez allí, la policía los puso a disposición judicial en la Audiencia Nacional, donde el juez les tomó declaración y les acusó de planear una serie de atentados terroristas contra la red de transporte público de Barcelona. Dada la gravedad de esa acusación, el juez mandó a los once detenidos a prisión sin fianza. Durante dos años, ese juez y el fiscal emprendieron una investigación marcada por la falta de pruebas materiales y por un testigo protegido cuya identidad y testimonio suscitaron gran polémica. Presentándose como un miembro de la célula terrorista de la que formaban parte los once encarcelados, ese testigo dijo haber participado en la planificación de los supuestos atentados y que, tras arrepentirse, llamó a la policía y confesó. Casi dos años más tarde, en diciembre de 2009, el juicio contra los once acusados comenzó en la Audiencia Nacional, donde el juez, pese a la polémica, dictó condenas de varios años (Prado et alii, 2009). 
Sin lugar a dudas, estas sentencias aumentaron la preocupación y las sospechas vecinales, políticas y mediáticas sobre los vínculos de Tariq ibn Ziyad, Madani Masjid, Shah Jalal Jame y la Jama'at at-Tabligh con redes terroristas. Asimismo, esas sospechas permearon las discusiones de los consejos de esos oratorios, vinculados a la organización y que, negando su vínculo con dichas redes, consolidaron sus disputas. Para el consejo de Tariq ibn Ziyad, la identidad y testimonio del testigo protegido, polémicos y difícilmente contrastables, sugerían un montaje contra los acusados, en su opinión inocentes, y contra el imarat y la influencia del oratorio y de la organización en El Raval. Para el consejo de Madani Masjid, ese montaje parecía más que posible, pero mostraba la necesidad de mantener cierta independencia y de formar una shura para compartir el liderazgo de la organización y salvaguardar su influencia en el barrio. De este modo, esa shura podría salvaguardar también la influencia y reputación de Fazail-e Amaal y Muntakhab Ahadith a nivel local. Para el consejo de Shah Jalal Jame, dicho montaje, ciertamente posible pero difícilmente demostrable, también mostraba cómo el sectarismo propio de musulmanes indios y paquistaníes, presente en Tariq ibn Ziyad y en Madani Masjid, suscitaba sospechas vecinales, políticas y mediáticas. Solo una shura formada en Shah Jalal Jame por bangladeshíes podría salvaguardar la reputación de la organización, de Fazail-e Amaal y Muntakhab Ahadith $\mathrm{y}$ de las posteriores discusiones con el fin último de guiar el proselitismo entre vecinos musulmanes.

La importancia dada a esos dos títulos y discusiones y al proselitismo llevó a nuevos debates y disputas, que esta vez contaron con nuevos interlocutores. En 2014, varios jóvenes bangladeshíes sugirieron que solo la formación académica permitiría la formación de una shura rejuvenecida que salvaguardara la reputación de dichos títulos y discusiones y que hiciera proselitismo de manera exitosa, en primer lugar, entre bangladeshíes. Partiendo de su experiencia en madrasas vinculadas a la Jama'at at-Tabligh y en markaz de la organización en Bangladesh, decidieron formar esa nueva shura a la que llamaron Sirat-e Mustaqeem Spain ('El camino recto en España'). En reuniones primero en Shah Jalal Jame y, posteriormente, al ser estas rechazadas por el consejo de este oratorio, en sus propios apartamentos, los miembros de Sirat-e Mustaqeem Spain discutieron un complejo programa de formación para prosélitos $\left(d a^{\prime} i\right)$. Este programa incluyó reglas estrategias para recitar (qira'at) y memorizar ( hafiz) el Corán y para leer y comentar dichos y hechos de Muhammad, así como para comentar y discutir Fazail-e Amaal y Muntakhab Ahadith. Ese programa incluyó también textos como Ar-Raheeq Al-Makhtum ('El néctar sellado'), una biografía de Muhammad de los años setenta publicada tanto en árabe y en urdu como en bengalí, y varias biografías de 
prosélitos, también publicadas en bengalí, como ejemplos para un proselitismo exitoso. Ese proselitismo, por supuesto, debía empezar preferiblemente por bangladeshíes para luego extenderse entre el resto de los vecinos musulmanes.

Un año más tarde, en 2015, un medio local, El Periódico de Cataluña, que había publicado numerosos artículos reafirmando la culpabilidad de «Los once de El Raval», publicó una entrevista con el testigo protegido en el juicio a esos once detenidos. En esta entrevista, este testigo, un paquistaní que confesó su vínculo con el tráfico de personas, reveló la falsedad de su testimonio durante dicho juicio, inducida por presiones que no identificó. Así, el testigo reveló también que los once encarcelados, por aquel entonces ya liberados y deportados a sus países, no tenían relación alguna con el terrorismo y eran inocentes de cualquier delito. Pese a la importancia de esta información, muy pocos medios hicieron un seguimiento, con la excepción de algún periódico local, como La Directa. No obstante, el boca a boca hizo su trabajo y el optimismo creció entre los miembros de Sirat-e Mustaqeem Spain, que consideraron que ese era el momento adecuado para encontrar su propio espacio en El Raval. En 2017 reunieron donaciones suficientes para alquilar los bajos de un edificio residencial en la calle Vistalegre, en el barrio. Tras las renovaciones pertinentes, eligieron a uno de ellos como imán y Darul Amaal como nombre para este oratorio, con capacidad para poco más de cien personas y que, a falta de varios permisos, empezó a funcionar en $2018^{4}$. Junto con las oraciones diarias, comenzaron a implementar el programa diseñado anteriormente, inscribiendo a asistentes jóvenes bangladeshíes para sesiones diarias de formación de prosélitos.

Para los miembros de Sirat-e Mustaqeem Spain, la formación de prosélitos debía garantizar que estos la transmitieran de manera adecuada a sus vecinos musulmanes y, en última instancia, simplemente, que estos recordaran sus hábitos y deberes, mencionados anteriormente. Sin embargo, recientemente, autores en medios y revistas especializadas han vuelto a mostrar su preocupación sobre la Jamáat at-Tabligh, su formación de prosélitos y su influencia entre los musulmanes. En particular, esos autores han sugerido que esa influencia, basada en subrayar hábitos y deberes específicos de los musulmanes, sugiere a su vez el rechazo hacia quienes no lo son (Jordán, 2009; Reinares, 2008). Tras los atentados de agosto de 2017 en Barcelona y Cambrils, pese a que los autores materiales procedían de Ripoll y ni estaban vinculados a la organización ni esta les había formado como prosélitos, los mismos autores han sugerido incrementar la vigilancia en Barcelona y, concretamente, en El Raval (Reinares, 2017; Reinares y García-Calvo, 2018). Los resultados de esa vigilancia parecen de difícil valo-

4 Darul Amaal obtuvo todos los permisos necesarios para abrir de forma oficial tras la redacción de este artículo, a principios de 2019. 
ración y, dados los precedentes, sugieren teorías de la conspiración que, por su parte, paradójicamente, tienen consecuencias que sí que podemos valorar. Pese a ello, nuevamente, las sospechas han permeado las discusiones de los consejos de los oratorios del barrio, incluyendo aquellas abiertas durante este siglo y vinculadas a otras organizaciones. Así pues, organizaciones tales como Dawat-e Islami ('Invitación al islam') y Minhaj ul-Quran ('Camino del Corán') han ensanchado el terreno de las disputas.

\section{Nuevas disputas}

Desde los ochenta, varios paquistaníes asistentes habituales a las oraciones, lecturas y discusiones en Tariq ibn Ziyad propusieron cantos dedicados a Muhammad y santos musulmanes como actividades complementarias en ese oratorio. En su opinión, esos cantos podían considerarse un deber de los musulmanes, honrando y mostrando respeto hacia figuras que, de ese modo, corresponderían con sus bendiciones. Asimismo, el recelo del consejo del oratorio hacia cualquier tipo de canto podía considerarse como un incumplimiento de un deber fundamental. Durante los noventa, con el recelo del consejo convertido en rechazo, quienes proponían cantos consolidaron su malestar y, con el cambio de siglo, decidieron solicitar la colaboración de Dawat-e Islami para encontrar una solución. Fundada en el Paquistán de los ochenta por Muhammad Ilyas Qadri para contrarrestar la influencia de la Jamáat at-Tabligh, esta organización ofrecía sus madani markaz ('centros de Medina') por todo el mundo para reunir donaciones y pagar la apertura y el mantenimiento de mezquitas y oratorios para cantos (Philippon, 2011). Así pues, tras alquilar y renovar los bajos de un edificio residencial en la calle Cabanes, en el barrio del Poblesec, colindante con El Raval, varios paquistaníes formaron un consejo que se encargó de elegir a otro paquistaní como imán y Fezan-e Madina como nombre para este oratorio. Con capacidad para más de doscientas personas y mejor insonorizado que Tariq ibn Ziyad, Madani Masjid y Shah Jalal Jame, este oratorio se convirtió en el espacio perfecto para la celebración de cantos.

Desde el principio, el vínculo de Fezan-e Madina con Dawat-e Islami otorgó a este oratorio una posición privilegiada para liderar una alternativa local a Tariq ibn Ziyad, Madani Masjid, Shah Jalal Jame y, en definitiva, la Jamáat at-Tabligh. Junto con los cantos, su consejo inscribió a muchos de los asistentes, sobre todo paquistaníes, y programó sus propias sesiones diarias para la formación de prosélitos. Las sesiones incluyeron reglas y estrategias para recitar y memorizar el Corán, para leer y comentar los dichos y hechos de Muhammad y, a partir de su publicación en 2013, para comentar y discutir Fezan-e Sunnat ('Bendiciones de 
la Sunna'). Para el consejo, títulos como este, en urdu por la propia organización, proporcionaban reglas para cantos, desde su pronunciación y ritmo hasta sus melodías, muchas veces acompañadas por un armonio, un pequeño instrumento de viento con teclado que produce un sonido parecido al del acordeón. Según el consejo, todo ello probaba que, a diferencia de los 'wahabíes' del resto de oratorios y organizaciones, incluyendo desde 2018 a Darul Amaal y Sirat-e Mustaqeem Spain, ellos dedicaban sus recursos a formar prosélitos con sensibilidad, es decir, en sus propias palabras, a formar 'sufíes' (tasawwuf, de los términos suf,' 'lana', asociada al misticismo, y safa, 'pureza', asociada también al misticismo). Por ello, el oratorio y su organización podían considerarse alternativas sufíes' destinadas a influir entre los vecinos musulmanes. Más allá del éxito, más bien relativo, esas alternativas generaron casi de inmediato sus propias disputas internas.

Para empezar, en el momento de su apretura, Fezan-e Madina generó el recelo de varios asistentes paquistaníes que destacaron las similitudes entre la Jamáat at-Tabligh y Dawat-e Islami, centrados en cuestiones doctrinales e incapaces de formar a prosélitos que conocieran El Raval. Por ese motivo, contactaron con Minhaj ul-Quran, una organización fundada en el Paquistán de los ochenta por Muhammad Tahir ul-Qadri para defender la celebración de cantos y promover que sus prosélitos 'sufíes' tuvieran nociones de cuestiones como la economía y los negocios. Con el fin de formar a esos prosélitos, la organización también ofrecía sus centros para reunir donaciones y pagar la apertura y mantenimiento de sus propias mezquitas y oratorios. En el barrio, el primero de esos oratorios, con un consejo y un imán paquistaníes, se estableció en los bajos de un edificio residencial en la calle Arc del Teatre. Casi una década después, con capacidad para poco más de cien personas, este oratorio resultó insuficiente. Unido a su mal estado de conservación, ello propició su cierre y la apertura de uno nuevo en la calle Erasme de Janer, con el mismo consejo e imán, llamado Camí de la Pau o Camino de la paz. Con capacidad para más de doscientas personas, este nuevo oratorio, insonorizado, empezó a celebrar cantos de forma regular y a inscribir a asistentes, sobre todo paquistaníes, para enseñarles nociones de economía y negocios, y discutieron sobre vivienda y trabajo en el barrio. Precisamente vivienda y trabajo resultarían clave para una nueva forma de hacer proselitismo a nivel local.

Durante los siguientes años, las discusiones en el oratorio promovieron que los prosélitos de Minhaj ul-Quran proporcionaran vivienda y trabajo a sus vecinos musulmanes, sobre todo a los paquistaníes. Junto con esto, dichas discusiones promovieron también el acercamiento de los prosélitos de la organización a distintos Gobiernos municipales, partidos políticos y sindicatos de trabajadores, muchas veces como miembros de estos, para organizar eventos de manera con- 
junta. Esos eventos, que en varias ocasiones contarían con la presencia de $\mathrm{Mu}$ hammad Tahir ul-Qadri, deberían promover el rechazo a prosélitos 'wahabíes', el diálogo interreligioso y el respeto hacia los vecinos musulmanes, una vez más, sobre todo los de los paquistaníes. Asimismo, tales eventos deberían consolidar una imagen alternativa no solo a los wahabíes y a la Jamáat at-Tabligh sino también a Dawat-e Islami y, concretamente, una imagen alternativa, sufí y de progreso. De un modo u otro, lo cierto es que, por lo menos a nivel político y mediático, la imagen de varias organizaciones ha seguido siendo más bien negativa, y, por el contrario, las iniciativas de Camí de la Pau o Camino de la Paz han sido por lo general bien recibidas (López Bargados, Lundsteen y Solé Arraràs, 2016). No obstante, más allá del éxito aparente de esas iniciativas, lo cierto es también que la llamada imagen alternativa, sufí y de progreso ha sufrido recientemente sus propias disputas internas y que, a su vez, esas disputas internas han producido múltiples divisiones. Veamos rápidamente de qué divisiones se trata.

Mientras los oratorios vinculados a la Jamáat at-Tabligh se dividían por motivos etnolingüísticos y generacionales, los oratorios vinculados a Minhaj ul-Quran y Dawat-e Islami dieron pie a divisiones similares. En 2014, nuevas generaciones de paquistaníes habían entrado ya en el consejo de Minhaj ul-Quran. Ese año, con la apertura de un nuevo oratorio de esta organización, de nuevo en la calle Arc del Teatre, los miembros más mayores del consejo reivindicaron su experiencia y tomaron el control de este nuevo espacio, con capacidad para poco más de cien personas. Asimismo, ese mismo año, algunos de esos miembros, recelosos de las relaciones con Gobiernos municipales, partidos políticos y sindicatos de trabajadores, decidieron vincularse a Dawat-e Islami, que, según ellos, preservaba mejor el espíritu sufí. Manteniendo cierta independencia con respecto a Fezan-e Madina, también vinculada a esa organización, lograron abrir un nuevo oratorio en la calle d'en Serra, en el barrio Gótico, colindante con El Raval, con capacidad para poco más de cien personas. Por su parte, simultáneamente, varios jóvenes bangladeshíes reclamaron su presencia en consejos de oratorios partidarios de cantos y del llamado espíritu sufí y reunieron donaciones suficientes para alquilar los bajos de un edificio residencial en la calle Aurora, en El Raval. Tras formar un consejo, este se encargó de elegir un imán con formación para cantos y Lotifia Fultoli Jame Masjid como nombre para este oratorio, con capacidad para otras cien personas y listo para programar cantos y formar prosélitos. 


\section{Nuevos terrenos}

Durante las entrevistas con los miembros de los consejos de los oratorios de El Raval y sus alrededores, estos indicaron que la formación para prosélitos y su proselitismo debían extenderse necesariamente a las conversaciones entre vecinos musulmanes en espacios cotidianos. Con el fin de observar esas conversaciones, desde 2018, decidí acompañar diariamente a prosélitos marroquíes, paquistaníes y bangladeshíes de todas las edades en sus lugares de trabajo, como locutorios, peluquerías, restaurantes y tiendas de alimentación, electrónica y de tejidos. Con mi diario de campo en mano, mi objetivo era tomar notas de dichas conversaciones, de sus contenidos y de sus dinámicas, así como de sus resultados. Para empezar, todos los prosélitos insistieron en la importancia de llevar la cabeza cubierta, ya fuera con turbante (amama o dastar) o gorro de oración (taqiya o topi), de llevar barba bien cuidada e ir perfumados y de vestir con chilaba (jellaba o jubba). Además, todos los prosélitos indicaron la importancia de hablar árabe para parafrasear el Corán y los dichos y hechos de Muhammad y en muchos casos urdu e incluso bengalí para parafrasear texto en esas lenguas. Asimismo, todos los prosélitos mencionaron la importancia de parafrasear esos textos y de hablar en un tono educado, pero también con determinación, es decir, sin levantar la voz, pero mostrando firmeza. En opinión de todos, solo de esa manera lograrían convencer de las propuestas de sus respectivas organizaciones, atrayendo donaciones para estas y sus oratorios, asistentes a sus actividades y, por qué no, futuros prosélitos.

Todos los prosélitos, a veces en grupo y otras de manera individual, lograron atraer donaciones, asistentes y futuros prosélitos, marroquíes, paquistaníes y bangladeshíes de todas las edades. No obstante, lo cierto es que muchos de sus interlocutores, también marroquíes, paquistaníes y bangladeshíes de todas las edades, tanto hombres como mujeres, respondieron de manera ambivalente. Más allá de su origen y de su edad y de si eran hombres o mujeres, todos consideraron que el Corán y los dichos y hechos de Muhammad debían inspirar los hábitos y deberes de los musulmanes, incluyendo la interacción con los demás y el proselitismo. Asimismo, todos consideraron el recelo a la celebración de cantos en oratorios razonable, una vez más, con el miedo a las protestas de los vecinos siempre presente. Sin embargo, todos dijeron que si académicos y sabios del islam (ulama) y líderes de organizaciones islámicas no habían alcanzado un acuerdo (ijma) sobre si dichos cantos eran sospechosos de politeísmo, prosélitos de esas organizaciones, formados en el barrio, difícilmente podían alcanzar ningún acuerdo. Por ello, todos dijeron querer seguir escuchando y conversando para, en el futuro, con independencia de las protestas de los vecinos por ruido, alcanzar dicho acuerdo y rechazar o promover definitivamente la celebración de cantos, que muchos, aun- 
que tímidamente, reconocieron disfrutar de vez en cuando. Mientras tanto, estas conversaciones seguirían marcadas por una incertidumbre (ghiraar) que muchos, sin demasiado pesar ni preocupación aparente, reconocieron también.

Para saber más sobre cómo tal incertidumbre condicionaba afiliaciones religiosas más allá de los prosélitos y entre sus interlocutores, también desde 2018, decidí entablar conversaciones con esos interlocutores. Para todos, dicha incertidumbre hacía difícil decantarse por una organización u otra, fuera la que fuera. En este sentido, de nuevo, todos suscribieron la promoción del Corán y de los dichos y hechos de Muhammad, así como de los hábitos y deberes de los musulmanes. Junto con esto, todos explicaron que esa promoción servía para extender discusiones a espacios cotidianos, como lugares de trabajo que, de lo contrario, serían ajenos a ellas. Por ello, explicaron que el desacuerdo (khilaf) que había caracterizado siempre al islam, paradójicamente, había permitido su supervivencia, también en espacios cotidianos, como lugares de trabajo, fueran los que fueran. Así pues, todos explicaron que, si bien todas las organizaciones merecían respeto por su contribución a esa expansión, el apoyo directo a sus prosélitos, ofreciéndoles donaciones, asistiendo a sus oratorios o planteándose convertirse en prosélitos, no era necesario. Según todos, tal indefinición no entraba, por consiguiente, en ninguna contradicción, además de que convertirse en prosélitos era prácticamente imposible por falta de tiempo, es decir, por el trajín que caracterizaba el día a día de la mayoría. Recordando siempre estas cuestiones, todos mencionaron que, al fin y al cabo y pese al sectarismo que caracterizaba las relaciones entre algunos musulmanes, bastaba con que la mayoría se respetase, como ocurría en el barrio.

Por último, hacia el final de mi trabajo de campo, ya 2019, estas conversaciones plantearon dos cuestiones más entre mis interlocutores que, como veremos, resultan importantes para la investigación. En primer lugar, para aquellos que llegaron al barrio hace décadas, este había permanecido siempre al margen del centro, como si desde el barrio Gótico y pasadas las Ramblas se hubiera dado la espalda a sus vecinos. De hecho, como sabemos, El Raval fue siempre eso, un arrabal, una periferia de marismas en la antigüedad, de albergues y hospitales en el Medievo, de fábricas y clase trabajadora durante el xix y principios del xx y de poblaciones marginales e inmigrantes a finales del xx (Aisa y Vidal, 2006). Pese a ello, o precisamente por ello, muchos de esos inmigrantes, concretamente los musulmanes, habían situado esa periferia, que con el nuevo siglo dejó de serlo (Fernández González, 2014), en un centro de organizaciones islámicas y discusiones entre musulmanes. Según mis interlocutores, esto reforzaba los prejuicios sobre el barrio, pero también hacía que sus vecinos musulmanes, anteriormente atentos 
a la producción de discursos religiosos en sus países y en otros países europeos, prestaran atención, sobre todo, a discursos producidos en el barrio. Así, mientras los centros de investigación sobre tales discursos siguen estando en África y Asia e incluso en Europa (López Bargados, Mapril y Sánchez García, 2014), sugiero considerar al barrio, pese a sus problemáticas, como un centro para la investigación sobre el islam, y no solo sobre inmigración, como hasta la fecha.

En segundo lugar, para aquellos que han llegado al barrio en los últimos años y que interactúan regularmente con prosélitos en espacios cotidianos, la sensación es que son precisamente esos espacios donde cuaja definitivamente el discurso religioso, del cual se consideran partícipes. En este sentido, la investigación sobre ese discurso ha adoptado las mezquitas y oratorios tanto en África y Asia como en Europa como escenarios principales, algo que yo he tratado de hacer en mi propio trabajo de campo (Peter y Ortega et alii, 2012). Sin embargo, recientemente, algunos autores han sugerido incorporar espacios cotidianos en el trabajo de campo para, en definitiva, discutir cómo aquello que se dice y hace en mezquitas y oratorios se reproduce o incluso varía en espacios más comunes, como lugares de trabajo (Alyanak, Ayuandini, Martín-Sáiz y Crossland-Marr, 2018). Como he tratado de mostrar en esta última sección, la incorporación de esos espacios plantea, a su vez, dos cuestiones más. La primera es que nos encontramos ante dos tipos de espacios distintos y, por consiguiente, ante dos tipos de producción de discurso distintos, sujetos a reglas y dinámicas distintas. Precisamente por esas diferencias, la etnografía, en este caso, sugiere que debemos ensanchar los límites espaciales y temporales que condicionan el estudio de las afiliaciones religiosas y el sectarismo, entendiendo que las posibles conclusiones son relativas, precisamente, a determinados espacios y momentos.

\section{Conclusiones}

Desde el principio, este artículo ha abordado el vínculo entre oratorios musulmanes, organizaciones islámicas y proselitismo, proponiendo no dar su naturaleza por sentada. En particular, este artículo ha descrito cómo el establecimiento de oratorios en el barrio de El Raval ha generado disputas por el control de esos espacios, priorizando determinadas prácticas sobre otras. Asimismo, estas páginas han descrito cómo esas disputas han llevado a sus participantes a invocar léxicos y textos específicos que, en última instancia, han consolidado, a lo largo del tiempo, afiliaciones con organizaciones específicas cuyas rivalidades, preexistentes, toman sentido localmente. Por otra parte, estas páginas han examinado, hacia el final, el modo en que esas afiliaciones contribuyen a la producción de discursos sobre el islam, pero al mismo tiempo, el modo en que tales afiliaciones y discursos varían 
en función de espacios y momentos. Por un lado, estas conclusiones se refieren a un caso concreto, el de El Raval, y por extensión, el de Barcelona, que, como anticipaba al principio, distinto al del resto de Cataluña y España. Sin embargo, por otro lado, más allá de las particularidades demográficas de estos escenarios, las dinámicas señaladas aquí pueden, y, de hecho, deben, ser comparables a las de otros. Dicho de otro modo, la mera descripción de dichos escenarios, especificando sus realidades étnico-lingüísticas e incluso religiosas, no basta para entender las dinámicas religiosas o sociales en general que los definen. Espero al menos haber ofrecido algunas claves al respecto.

\section{Agradecimientos}

En primer lugar, agradezco a Jordi Moreras su invitación para participar con este artículo en el este número especial, además de a Alberto López Bargados y a los revisores anónimos por sus comentarios para mejorar estas páginas. En segundo lugar, agradezco a los participantes en mi investigación por su confianza, disponibilidad y generosidad, sin las cuales tanto esa investigación como este artículo habrían resultado imposibles. 


\section{Referencias}

Aisa, Ferran y Mei Vidal (2006). El Raval: un espai al marge. Barcelona: Base.

Alyanak, Oguz; Ayuandini, Sherria; Martín-Sáiz, Guillermo y Crossland-Marr, Lauren (s. f.). «Shadowing as a Methodology. Notes from Research in Strasbourg, Amsterdam, Barcelona, and Milan». En G. Gmelch y Petra Kuppinger (eds.). Urban Life. Readings on the Anthropology of the City ( $6{ }^{a}$ ed). Long Grove, IL: Waveland Press.

Fernández González, Miquel (2014). Matar al Chino: entre la revolución urbanistica y el asedio urbano en el barrio del Raval de Barcelona. Barcelona: Virus. Jordán, Javier (2009). «Políticas de prevención de la radicalización violenta en Europa: Elementos de interés para España». Revista Electrónica de Ciencia Penal y Criminología, 5: 1-25.

López Bargados, Alberto; Mapril, José y Sánchez García, José (2014). «Vivir el islam en el sur de Europa: la construcción de la transnacionalidad desde una perspectiva religiosa». Revista de Estudios Internacionales Mediterráneos, 16, versión digital.

López Bargados, Alberto; Lundsteen, Martin y Solé Arraràs, Ariadna (2016). La pràctica religiosa de les comunitats musulmanes de Barcelona: expressions i problemàtiques. Barcelona: SAFI- Stop als fenòmens islamòfobs a Catalunya.

Malik, Mohammad Manzoor (2017). «Tablighi Jamaat on Trial: Need of Reformation (tajdeed) and Reorganization (tanzeem)». Open Science Framework, version digital.

Martín-Sáiz, Guillermo (2014). «Espacio público e islam transnacional: A propósito de la Jamáat at-Tabligh en Barcelona». Revista de Estudios Internacionales Mediterráneos, 16, versión digital.

Martín-Sáiz, Guillermo (2015). «Cuerpo, tiempo y espacio en el estudio de comunidades musulmanas en España: el caso de la Jamáat at-Tabligh», Religiâo E Sociedade, 35(2): 96-122.

Martínez-Ariño, Júlia; Griera, Maria M.; García-Romeral, Gloria y Forteza, María (2011). «Inmigración, diversidad religiosa y centros de culto en la ciudad de Barcelona». Migraciones, 30: 101-133.

Masud, Muhammad Khalid (2000). «The Growth and Development of the Tablighi Jama'at in India». En Muhammad Khalid Masud (ed.). Travellers in Faith: Studies of the Tablighi Jama'at as a Transnational Islamic Movement for Faith Renewal. Leiden: Brill.

Metcalf, Barbara D. (ed.). Making Muslim Space in North America and Europe. Berkeley y Los Angeles: University of California Press, 1996. 
Metcalf, Barbara D. (2009). "Jihad in the Name of God: A Tablighi Jama'at Account of a Mission in India». En Barbara D. Metcalf (ed.). Islam in South Asia in Practice. Princeton: Princeton University Press.

Moreras, Jordi (1999). Musulmanes de Barcelona: espacios y dinámicas comunitarias. Barcelona: CIDOB Edicions.

Moreras, Jordi (2004). "¿Ravalistán? Islam y configuración comunitaria entre los paquistaníes de Barcelona». Revista CIDOB d'Afers Internacionals, 68: 119-132.

Moreras, Jordi (2009). Una mesquita al barri: conflicte, espai públic i integració urbana dels oratoris musulmans a Catalunya. Barcelona: Fundació Jaume Bofill.

Peter, Frank y Ortega, Rafael (eds.) (2012). Los movimientos islámicos transnacionales y la emergencia de un «islam europeo». Barcelona: Bellaterra.

Philippon, Alix (2011). «Sunnis against Sunnis: The Politization of Doctrinal Fractures in Pakistan». The Muslim World, 101(2): 347-368.

Planet, Ana I. (1998). Melilla y Ceuta: espacios-frontera hispano-marroquies. Ciudad Autónoma de Melilla: Ciudad Autónoma de Melilla.

Prado, Abdennur; Martínez, Albert; López Bargados, Alberto; Salellas Vilar, Benet; Fernàndez, David y Rivera Beiras, Iñaki (2009). Rastros de Dixan: islamofobia y construcción del enemigo en la era post 11-S. Barcelona: Virus Editorial.

Reinares, Fernando (2008). "Yihadismo’ paquistaní en Barcelona». El País, versión digital, 29 de enero de 2008.

Reinares, Fernando (2017). Al-Qaeda's Revenge: The 2004 Madrid Train Bombings. New York City, NY: Columbia University Press.

Reinares, Fernando y Carola García-Calvo (2018). «Un análisis de los atentados terroristas de Barcelona y Cambrils». Análisis del Real Instituto Elcano, $12: 1-20$.

Sikand, Yoginder (2000). The Origins and Development of the Tablighi Jama'at (1920s-1990s): A Cross-Country Comparative Study. Hyderabad: Orient Longman.

Soysal, Yasemin Nuhoğlu (1994). Limits of Citizenship. Migrants and Postnational Membership in Europe. Chicago: Chicago University Press.

Tarrés Chamorro, Sol (2012). «La Yamaat al-Tabligh en España». En Frank Peter y Rafael Ortega (eds.). Los movimientos islámicos transnacionales y la emergencia de un «islam europeo»". Barcelona: Bellaterra.

Vertovec, Steven y Peach, Ceri (eds.) (1997). Islam in Europe. The Politics of Religion and Community. New York: Palgrave Macmillan. 